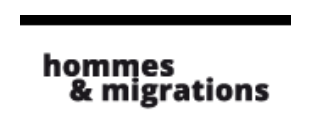

Hommes \& migrations

Revue française de référence sur les dynamiques

migratoires

$1334 \mid 2021$

Exposer le racisme et l'antisémitisme

\title{
Ali Guenoun, La question kabyle dans le nationalisme algérien, 1949-1962. Comment la crise de 1949 est devenue la crise " berbériste "
}

Préface d'Omar Carlier, postface de Mohamed Harbi, Vulaines-sur-Seine, éd. du Croquant, 2021, 512 p., $20 €$.

\section{Mustapha Harzoune}

\section{(2) OpenEdition}

12 Journals

\section{Édition électronique}

URL : https://journals.openedition.org/hommesmigrations/13143

DOI : 10.4000/hommesmigrations. 13143

ISSN : 2262-3353

\section{Éditeur}

Musée national de l'histoire de l'immigration

\section{Édition imprimée}

Date de publication : 1 juillet 2021

Pagination : 232-233

ISBN : 978-2-919040-58-2

ISSN : 1142-852X

\section{Référence électronique}

Mustapha Harzoune, « Ali Guenoun, La question kabyle dans le nationalisme algérien, 1949-1962.

Comment la crise de 1949 est devenue la crise «berbériste » ". Hommes \& migrations [En ligne], 1334 |

2021, mis en ligne le 01 juillet 2021, consulté le 04 février 2022. URL : http://journals.openedition.org/ hommesmigrations/13143; DOI : https://doi.org/10.4000/hommesmigrations.13143 


\section{La question kabyle dans le nationalisme algérien, 1949-1962. Comment la crise de 1949 est devenue la crise « berbériste »}

Ali Guenoun, préface d'Omar Carlier, postface de Mohamed Harbi, Vulaines-sur-Seine, éd. du Croquant, 2021, 512 p., $20 €$

Longtemps, les Kabyles furent majoritaires en immigration. Souvent, cette réalité sociologique disparaît derrière le poids des idéologies et des appareils, au point d'invisibiliser les hommes et leurs actions. Placée au centre de cette

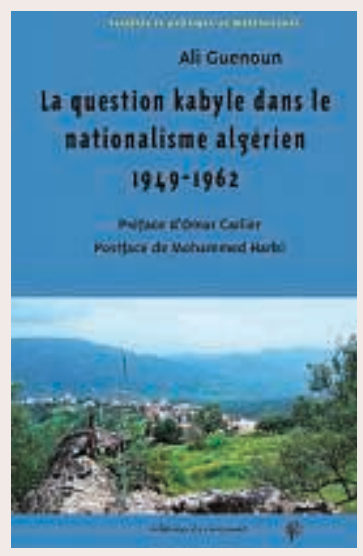

étude serrée, la crise de 1949 au sein du mouvement nationaliste algérien est partie de France, sans doute en mars 1949. La police ne la signale qu'à la mi-juin 1949, à l'occasion d'une bagarre dans une salle des fêtes d'Aubervilliers. Elle se termine en 1950, en mars pour les uns, en décembre pour les autres.

Elle sera portée par de jeunes nationalistes, éduqués et formés, vite montés dans l'appareil du parti. Crise multidimensionnelle, elle ne fut pas une crise "berbère», comme ses détracteurs s'appliquent, depuis toujours, à la qualifier. Pour cette nouvelle génération, il s'agissait à la fois de "contester»le fonctionnement et la stratégie du PPA-MTLD dirigé par Messali Hadj, d'offrir un cadre démocratique au mouvement et à l'Algérie, et d'assumer l'héritage culturel pluriel de la terre algérienne. C'est une Algérie algérienne qu'ils promeuvent versus une définition uniciste de la nation (arabe) religieuse (musulmane), peu démocratique (culte du chef) et sans concertation (absence de débat). On sait ce qu'il advint à l'indépendance. Ali Guenoun traite cette crise sur le fond, pas comme une parenthèse. 1949, comme plus tard 1962 sont deux crises majeures quant au devenir de la nation algérienne.

L'auteur en décrit l'origine et la genèse: le rôle de l'école française dans l'éveil de la conscience nationale chez ces premiers lettrés 
à prendre les armes, de l'immigration comme de l'organisation du parti en Kabylie et ses ramifications en Algérie. Il montre que cette contestation fut éclatée, entre France et Algérie, entre plusieurs groupes, plusieurs régions, qu'elle fut portée par des berbérophones et des arabophones, des modérés et des «berbéristes» radicaux, des «berbéristes» et des «arabistes», qu'elle fut sans coordination face à la machine répressive du parti. Ni complot, ni régionalisme donc. Qu'il s'est agi aussi, en refusant son modèle jacobin, d'une émancipation radicale d'avec la puissance coloniale, d'une décolonisation... des esprits.

1949 marque un tournant. Les contestataires seront balayés, idéologiquement, accusés de «berbérisme», de «trahison» et marqués du sceau de la suspicion, ce qui restera commode pour discréditer toute velléité de réforme. Ils seront même accusés... d'«islamophobie» par le plus virulent de leur détracteur (Y. Ben Khedda). Serait-ce la première et révélatrice occurrence du mot? Le nationalisme algérien n'a jamais goûté les intellectuels, beaucoup seront éliminés. À Paris et dans les maquis, la violence s'impose comme réponse à toute contestation.

Cela, Ali Guenoun le décortique, livre une sociologie précise des acteurs, fait l'inventaire des lieux, notamment des cafés dans l'immigration, à la fois espace de propagande, d'opposition, de lutte et de violence. Il fouille les enjeux et les impasses de la crise, en repère les amnésies et les resucées, les «thèses et foutaises», pendant et après la guerre. Il y est aussi question de mémoire: mémoire des victimes et de leur famille, mémoire instrumentalisée, souillée, «empêchée», invisibilisée - notamment dans les entreprises mémorielles franco-algériennes. La plume, précise, jalouse de l'autonomie du chercheur, ne cache pas l'empathie de l'historien
- lecteur de Feraoun - pour les acteurs et les victimes de cette histoire qui court sur treize ans. Pour autant, elle se refuse à toute compromission, à tout militantisme. Elle expose les faits, pose des hypothèses, quitte à fâcher les doxas nationalistes ou communautaires, à déchirer les silences et les solidarités des anciens camarades de lutte ou à heurter «la terrible loi du nif». En exergue, l'auteur a placé une citation d'Amar Imache: "La vérité seule est constructive. [...] S'il est une chose qu'un peuple ne doit pas laisser déformer, ternir ou voler, c'est son Histoire. » Histoire algérienne, française, francoalgérienne. Histoire de l'immigration.

M. H. 